\title{
Otizmli Çocuğu Olan Anne Babaların Yaşam Doyumu, Sosyal Destek ve Umut Düzeyleri
}

\section{Life Satisfaction, Social Support and Hope Parents with Children with Autism}

\author{
${ }^{1}$ Hüseyin MUTLU, ${ }^{2}$ Gülser VARDARCI KACAR, ${ }^{3}$ Alev GIRLI \\ ${ }^{1}$ Sorumlu Yazar, Doktora öğrencisi, Özel Ĕgitim Bölümü, Eğitim Bilimleri Enstitüsü, Dokuz Eylül \\ Üniversitesi, Türkiye, hmutlu145@gmail.com, (https://orcid.org/0000-0002-1036-9528) \\ ${ }^{2}$ Doktora öğrencisi, Özel Ĕ̌itim Bölümü, Eğitim Bilimleri Enstitüsü, Dokuz Eylül Üniversitesi, \\ Türkiye, gulservardarci@gmail.com, (https://orcid.org/0000-0002-8370-4279) \\ ${ }^{3}$ Doç. Dr., Emekli Öğretim Üyesi, alev.girli@gmail.com, (https://orcid.org/0000-0002-4146- \\ 3103)
}

Geliș Tarihi: 03.02.2021

Kabul Tarihi: 27.12.2021

ÖZ

Bu araştırmanın amacı otizmli çocuğu olan anne babaların yaşam doyumları, algıladıkları sosyal destek ve umut düzeyleri arasındaki ilişsinin bazı değişkenler açısından incelenmesidir. Çalışmada betimsel araştırma yöntemlerinden genel tarama modeli kullanılmıştır. Araştırmaya otizmli çocuğu olan 151 anne baba katılmıştır. Araştırma verileri, Çok Boyutlu Algılanan Sosyal Destek Ölçeği (Zimet, Dahlem, Zimet ve Farley, 1988), Sürekli Umut Ölçeği (Snyder, LaPointe, Crowson ve Early, 1991) ve Yaşam Doyumu Ölçeğinin (Diener, Emmons, Larsen ve Griffin, 1985) çevrimiçi platformlar üzerinden yanıtlanması ile toplanmıştır. Verilerin alınmasında sonra gerekli istatistiksel işlemler yapılarak araştırma sonuçları elde edilmiştir. Araştırma sonuçlarına göre otizmli çocuğu olan anne babaların yaşam doyumu, algıladıkları sosyal destek ve umut düzeylerinin orta derecede olumlu olduğu görülmüştür. Otizmli çocuğu olan anne babaların algıladıkları yaşam doyumu, sosyal destek ve umut düzeyleri arasında orta düzeyde anlamlı bir korelasyon saptanmıştır. Algılanan sosyal destek ve umut düzeyinin ebeveynlerin yaşam doyumlarının $\% 56$ 'sını yordadığı, sosyal desteğin ise tek başına yaşam doyumunun \%48,4'ünü açıkladığı saptanmıştır. Ayrıca anne babaların çalışma ve ekonomik durumlarının yaşam doyumu, algılanan sosyal destek ve umut düzeyleri ile ilişkili olduğu bulunmuştur. Ebeveynlerin yaşı ve yaşam doyumları arasındaki ilişkinin de istatistiksel olarak anlamlı olduğu belirlenmiştir.

Anahtar Kelimeler: Otizm, yaşam doyumu, sosyal destek, umut.

\begin{abstract}
The aim of this study is to examine the relationship between life satisfaction, perceived social support and hope levels of parents with children with autism in terms of some variables. General survey model, one of the descriptive research methods, was used in the study. 151 parents with children with autism participated in the study. The research data were collected by answering the Multidimensional Perceived Social Support Scale (Zimet, Dahlem, Zimet ve Farley, 1988), the Dispositional Hope Scale (Snyder, LaPointe, Crowson ve Early, 1991) and the Life Satisfaction Scale (Diener, Emmons, Larsen ve Griffin, 1985) via online platforms.After the data was collected, the research results were obtained by performing the necessary statistical processes. According to the results of the study, it was observed that the life satisfaction, perceived social support and hope levels of the parents of children with autism were moderately positive. A moderately significant correlation was found between the perceived life satisfaction, social support and hope levels of the parents of children with autism. It was determined that perceived social support and hope level predicted $56 \%$ of parents' life satisfaction, while social support alone explained $48.4 \%$ of life satisfaction. In addition, it was found that the work and economic status of the parents were related to their
\end{abstract}


life satisfaction, perceived social support and hope levels. It was determined that the relationship between the parents' age and life satisfaction was also statistically significant.

Keywords: Autism, life satisfaction, social support, hope.

\section{GíRiş}

Otizm, sosyal becerilerde sınırlılıklar, iletişimde bozukluklar ve tekrarlayıcı davranışlarla karakterize olan gelişimsel bir bozukluktur (American Psychiatric Association, 2013). Geçmişten günümüze görülme sıklığı giderek artan otizmin, günümüzde her 68 çocuktan birinde görüldüğü ve bireylerin yașamları için birtakım zorlukları da beraberinde getirdiği belirtilmektedir (Bearss, Burrell, Stewart ve Schaill, 2015). Otizmli bireylerin yemek yeme ve tuvalet eğitimi gibi öz bakım ihtiyaçları ile birlikte sosyalleşme, finansal bağımsızlık, akademik başarı (Robertson, 2010), mesleki başarı ve kişilerarası ilişkiler (Mazurek, 2014) gibi günlük yaşamın diğer alanlarında da sorunlar yaşadıkları bildirilmiştir. Araştırmalar, otizmli bireylerin bu yaşadıklarının, sadece kendi yaşamlarını değil, aynı zamanda ailelerinin yaşamlarını da olumsuz yönde etkilediğini göstermiştir (Hayes ve Watson, 2013).

Otizmli çocuğu olan ailelerin, normal gelişim gösteren çocuklu ailelere kıyasla, yüksek düzeyde stres, kaygı, depresyon yaşadığı (Estes, Munson, Dawson, Koehler, Zhou ve Abbott 2009; Hayes ve Watson, 2013; Rivard, Terroux, Parent-Boursier, ve Mercier, 2014; Sabih ve Sajid, 2008; Sencar, 2007), bununla birlikte umut düzeylerinin de düşük olduğu (Çengelci, 2009; Naci ve Koletsi, 2021) bulunmuştur. Alanyazın incelendiğinde umut duygusu ile depresyon, stres ve kaygı arasında yüksek düzeyde anlamlı bir ilişsinin olduğu görülmektedir (Cunningham, Gunn, Alladin ve Cawthorpe, 2008; Landis, Gaylord-Harden, Malinowski, Grant, Carleton ve Ford, 2007). Umut, bireylerin geleceğe yönelik iyimser ya da kötümer olma durumlarına göre değişen bir duygu durumudur. Umut düzeyinin düşük olduğu durumda kişiler, hiçbir şeyin iyiye gitmeyeceğine inanmaktadırlar (Tanaka, Sakamoto, Ono, Fujihara ve Kitamura, 1996). Landis ve diğerleri (2007), kontrol edilemez olarak algılanan stresörlerin umut düzeyini anlamlı şekilde düşürdüğünü bildirmişlerdir. Otizmli bir çocuğa sahip olma durumunun da kontrol edilemez stresörlerden biri olduğu belirtilmektedir (Vetrayan, Daud ve Paulraj, 2013). Bununla birlikte araştırmalar otizmli çocuğun duygusal ve davranışsal problemlerinin arttıkça, aile işlevselliğinin bozulduğunu (McStay, Dissanayake, Scheeren, Koot ve Begeer, 2014; Pozo, Sarria, ve Brioso, 2014), ebeveynlerin fiziksel ve psikolojik sağlığının (Estes ve diğ., 2009; Farrugia, 2009; Vasilopoulou ve Nisbet, 2016; Yorke, White, Weston, Rafla, Charman, Simonoff, 2018) ise olumsuz etkilendiğini göstermektedir. $\mathrm{Bu}$ nedenle otizmli bireyin sergilediği problem davranışların fazlalığı ve yoğunluğunun, anne babaların umut düzeyleri üzerinde en fazla olumsuz etkiye sahip etmen olduğu belirtilmektedir (Çengelci, 2009).

Otizmli çocuğun problem davranışlarının, ebeveynlerin umut düzeyleri üzerindeki olumsuz etkisinin yanı sıra yaşam doyumlarını da olumsuz etkilediği belirtilmektedir (Lu, Yang, Skora, Wang, Cai, Sun, ve Li, 2015). Yaşam doyumu, bireylerin yaşamlarına ilişkin yaptıkları öznel bir değerlendirmedir. Bu değerlendirmede bireyler mevcut durumları ile olmak istedikleri durum arasında bir karşılaştırma yaparak yaşamdan aldıkları doyuma karar vermektedirler (Diener, 1984). Yapılan çalışmalarda otizmli çocuğu olan anne babaların normal gelişim gösteren çocuğa sahip ebeveynlere göre daha düşük düzeyde yaşam doyumu algıladıkları bildirilmiştir (Cho ve Kahng, 2015; Lu ve diğerleri, 2015). Özellikle, otizmli çocuğun problem davranışlarının yoğunluğu arttıkça ebeveynlerin algıladığı bakıma ilişkin sorumluluğun da önemli ölçüde arttığ (Marsack ve Perry, 2018), bu nedenle de ailelerin fiziksel olarak daha fazla yorulduğu (Oti-Boadi, Asanti ve Malm, 2020; Swaab, McCormack ve Campbell, 2017), ekonomik sorunlar yaşadığ1 (Cidav, Marcus ve Mandell, 2012; Hoefman ve diğ., 2014) ve kendi yaşam ihtiyaçlarına zaman ayıramadıkları saptanmıştır (Hines, Balandin ve Togher, 2014; Nicholas, MacCulloch, Roberts, Zwaigenbaum ve McKeever, 2020). 
Otizmli çocuğu olan anne babaların genel olarak umut düzeylerinin ve yaşam doyumlarının düşük olduğu bildirilse de (Barker, Hartley, Seltzer, Floyd, Greenberg ve Orsmond, 2011; Cho ve Khang, 2015) bazı ailelerin bu durumla baş edebildikleri (Kuhn, Ford ve Dawalt, 2018) ve otizmli bir çocuk ile yaşamaya uyum sağladıkları görülmektedir (Patterson, 2002). Bu uyum üzerinde etkili olan en önemli değişkenlerden birinin de algılanan sosyal destek olduğu belirtilmektedir (Ekas, Lickenbrock ve Whitman, 2010). Otizmli çocuğu olan ailelerde algıllanan sosyal destek sistemleri ile ilgili birçok çalışma yapılmıştır. (Karpat ve Girli, 2012; Özkubat, Özdemir, Selimoğlu ve Töret, 2014; Tunç ve Özkardaş, 2020). Yapılan çalışmalar ebeveynlerin, otizmli çocuklarına uyum sağlamasında algılanan sosyal desteğin önemli bir belirleyici olduğunu göstermektedir (Derguy, Bailara, Michel, Roux ve Bouvard, 2016). Bununla birlikte algilanan sosyal destek düzeyinin arttıkça anne babaların umut düzeylerinin arttığı (Karadă̆, 2009), depresyonun azaldığ 1 (Ekas ve diğ., 2010), algılanan yaşam kalitesi ve yaşam doyumunun da arttığ 1 bildirilmiştir (Khanna, Madhavan, Smith, Patrick, Tworek ve Becker Cottrill, 2011; Lu ve diğ., 2015; Zablotsky, Bradshaw ve Stuart, 2013).

Yukarıda da belirtildiği gibi, otizmli çocuğu olan anne babaların umut düzeyleri ve yaşam doyumu algıları üzerinde en olumlu etkiye sahip değişkenlerden birinin algılanan sosyal destek olduğu görülmektedir (Lu ve diğ., 2015; Marsack ve Perry, 2018). Bu nedenle yaşam doyumu, algılanan sosyal destek ve umut düzeyi arasındaki ilişkinin incelenmesinin, otizmli çocuğu olan ailelerinin yaşam kalitelerini arttırabilmek ve yaşadıkları güçlüklerle daha kolay baş etmelerini sağlayacak etkili müdahaleler hazırlayabilmek açısından önemli olduğu düşünülmektedir. $\mathrm{Bu}$ araştırmada otizmli çocuğu olan anne babaların yaşam doyumları, algıladıkları sosyal destek düzeyleri ve umut düzeylerinin birbirleri ile ve çalışma durumu, yaş, ekonomik durum gibi demografik değişkenlerle ilişkisinin araştırılması amaçlanmaktadır. Bu doğrultuda araştırma soruları şu şekildedir:

1. Otizmli çocuğu olan anne babaların algıladıkları sosyal destek, yaşam doyumu ve umut düzeyleri arasında ilişki var mıdır?

2. Otizmli çocuğu olan anne babaların algıladıkları sosyal destek ile çalışma durumu arasında ilişki var mıdır?

3. Otizmli çocuğu olan anne babaların umut düzeyleri ile çalışma durumu arasında ilişki var midir?

4. Otizmli çocuğu olan anne babaların yaşam doyumları ile çalışma durumu arasında ilişki var midır?

5. Otizmli çocuğu olan anne babaların algıladıkları sosyal destek ile yaş değişkeni arasında ilişki var mıdır?

6. Otizmli çocuğu olan anne babaların umut düzeyleri ile yaş değişkeni arasında ilişki var midir?

7. Otizmli çocuğu olan anne babaların yaşam doyumları ile yaş değişkeni arasında ilişki var midir?

8. Otizmli çocuğu olan anne babaların algıladıkları sosyal destek ile ekonomik durum arasında ilişki var mıdır?

9. Otizmli çocuğu olan anne babaların umut düzeyleri ile ekonomik durum arasında ilişki var midir?

10.Otizmli çocuğu olan anne babaların yaşam doyumları ile ekonomik durum arasında ilişki var midir?

\section{YÖNTEM}

\subsection{Araştırmanın Modeli}

$\mathrm{Bu}$ araştırmada, betimsel araştırma modellerinden tarama yöntemi kullanılmıştır. Genel tarama modeli ile gerçekleştirilen bu araştırmada, iki ve daha çok sayıdaki değişkenin birlikte 
değişim derecesinin belirlemesi amaçlanmaktadır. Ayrıca veri toplama araçlarına dayalı olarak elde edilecek verilerin çözümlenmesinde karşılaştırma türü ilişsisel betimlemelere de yer verilmiştir (Karasar, 2016).

\section{2. Çalışma Grubu}

Araştırmanın çalışma grubu otizmli çocuğu olan gönüllü 151 anne babadan oluşmuştur. Araştırmaya katılan anne babalara ilişkin sosyo-demografik bilgiler Tablo 1'de verilmiştir.

Tablo 1. Katılımcılara İlişkin Demografik Değişsenler Tablosu

\begin{tabular}{lll}
\hline Cinsiyet & $\mathrm{n}$ & Yüzde \% \\
\hline Kadın & 131 & 86,7 \\
Erkek & 20 & 13,3 \\
\hline Yaş & & \\
\hline $18-27$ & 6 & 3,9 \\
$28-35$ & 45 & 29,8 \\
$36-42$ & 63 & 41,7 \\
$43-50$ & 26 & 17,3 \\
51 ve üstü & 11 & 7,3 \\
\hline Çalışma Durumu & & 65,6 \\
Çalışmıor & 99 & 26,5 \\
Tam Zamanlı Çalışıyor & 40 & 7,9 \\
Yarı Zamanlı Çalışyor & 12 & \\
\hline Ekonomik Durum & & 41,1 \\
\hline Kötü & 62 & 40,4 \\
Orta & 61 & 18,5 \\
İyi & 28 & 100 \\
\hline Toplam & 151 & \\
\hline
\end{tabular}

\subsection{Veri Toplama Araçları}

Araştırmada kullanılan ölçme araçları bu bölümde yer almaktadır. Çalışma öncesinde ölçeklerin kullanımı için bu araçların adaptasyon, geçerlik ve güvenirlik çalışmalarını yapan araştırmacılardan izinler alınmıştır.

\subsubsection{Sürekli Umut Ölçeği (SUÖ)}

On beş yaş ve üstündeki bireylerin sürekli umut düzeylerini belirlemek amacı ile Snyder ve diğerleri (1991) tarafından geliştirilen SUÖ 12 madde ve iki alt boyuttan oluşmaktadır. Alternatif Yollar Düşüncesi ve Eyleyici Düşünce olarak isimlendirilen alt boyutların her biri dörder madde ile ölçülmektedir. Bu dörder maddenin bir tanesi geçmişe, iki tanesi içinde bulunulan zamana, bir tanesi de geleceğe yönelik ifadeleri içermektedir. Diğer dört madde umutla ilgisi olmayan dolgu maddelerden oluşmaktadır.

Bireylerden maddelerdeki ifadelerin kendi durumlarını yansıtma derecelerini, kesinlikle yanlış (1), çoğunlukla yanlış (2), oldukça yanlış (3), biraz yanlış (4), biraz doğru (5), oldukça doğru (6), çoğunukla doğru (7) ve kesinlikle doğru (8) şeklinde oluşturulan Likert tipi sekizli bir derecelendirme ölçeği üzerinde işaretlemeleri istenmektedir. Ölçekten alınabilecek en düşük puan 8 , en yüksek puan 64 'tür.

Ölçeğin Türk diline uyarlaması, geçerlik ve güvenirlik çalışmaları Tarhan ve Bacanlı (2015) tarafından yapılmıştır. Ölçeğin Türkçe formunun orijinal ölçeğe benzer şekilde iki faktörlü bir yapı sergileyip sergilemeyeceğini belirlemek amacı ile açımlayıcı faktör analizi yapılmıştır. 
Açımlayıcı faktör analizi ile ölçeğin boyutları incelenmiştir. Yapılan analiz sonucunda ölçeğin iki faktörlü yapısını koruduğu, Cronbach Alpha katsayısı .83 ve KMO değeri .86 olarak bulunmuştur. Test tekrarı yöntemi ile yapılan güvenirlik çalışmasında ölçeğin güvenirlik katsayıları 3 hafta ara ile $.85,8$ hafta ara ile .73 ve 10 hafta ara ile .76 olarak bulunmuştur.

\subsection{2. Çok Boyutlu Algılanan Sosyal Destek Ölçeği (ÇBASDÖ)}

Zimet ve diğerleri (1988) tarafından geliştirilen Çok Boyutlu Algılanan Sosyal Destek Ölçeği, üç farklı kaynaktan (aile, arkadaş ve özel bir insan) alınan sosyal desteğin yeterliliğini öznel olarak değerlendiren, 12 maddeden oluşan bir ölçektir. Katılımcılar ölçekte yer alan maddeleri, bir ucunda kesinlikle hayır (1) diğer ucunda kesinlikle evet (7) ifadelerinin olduğu, 12-3-4-5-6 ve 7 rakamlarından oluşan bir dereceleme sisteminden işaretleyerek yanıtlamaktadırlar. ÇBASDÖ, her biri dört maddeden oluşan üç alt boyuta sahiptir. Ölçeğin alt boyutları Aileden Alınan Sosyal Destek, Arkadaşlardan Alınan Sosyal Destek ve Özel Bir İnsansan Alınan Sosyal Destek'tir. Ölçekten alınabilecek en düşük puan 12, en yüksek puan ise 84'tür (Meral ve Cavkaytar, 2012).

Meral ve Cavkaytar (2012) ölçeğin uyarlama, geçerlik ve güvenirliğini otizmli çocuğu olan aileler üzerinde incelemişlerdir. Yapılan faktör analizi sonucunda faktör yüklerinin .71. ile .87 aralığında olduğu saptanmıştır. Çalışmada ölçeğin bütünü için Cronbach Alpha güvenirlik katsayısı .91, alt boyutlar açısından; aileden alınan destek için .90, arkadaşlardan alınan destek için .91, özel birinden alınan destek için .89 olarak hesaplanmıştır.

\subsubsection{Yaşam Doyum Ölçeği}

Yaşam Doyum Ölçeği Diener ve diğerleri (1985) tarafından geliştirilmiştir. Ölçek tek boyutlu ve 5 maddeden oluşmaktadır. Ölçek yanıtları hiç katılmıyorum (1), çok az katılıyorum (2), orta düzeyde katılıyorum (3), büyük oranda katılıyorum (4) ve tamamen katıllyorum (5) şeklinde oluşturulan 5'li likert tipi derecelendirme ile alınmaktadır. Ölçekten alınabilecek en düşük puan 5, en yüksek puan ise 25'tir (Dağl1 ve Baysal, 2016).

Ölçeğin dilimize uyarlaması Dağlı ve Baysal (2016) tarafindan yapılmıştır. Ölçek önce dilimize çevrilmiş ve dilsel olarak geçerliğine bakılmıştır. Ölçeğin dil geçerliğinin .92 olduğu bulunmuştur. Yaşam Doyumu Ölçeğinin Cronbach Alpha güvenirlik katsayıs1, 0,88 olarak hesaplanmıştır (Dağlı ve Baysal, 2016).

\subsubsection{Kişisel Bilgi Formu}

Araştırmada katılımcıların sosyo-demografik özelliklerini belirlemek amacıyla araştırmacılar tarafından geliştirilen kişisel bilgi formu kullanılmıştır.

\subsection{Verilerin Toplanması ve Analizi}

Araştırma 2018-2019 öğretim yılının güz döneminde gerçekleştirilmiştir. Ölçeklerin uygulanabilmesi için öncelikle ölçeklerin adaptasyon, geçerlik ve güvenirlik çalışmalarını yapan araştırmacılardan ölçeklerin kullanımına ilişkin izinler alınmıştır. Daha sonra Dokuz Eylül Üniversitesi Eğitim Bilimleri Enstitüsüne etik kurul başvurusu yapılmıştır. Etik kurul başvurusu 20/12/2018 tarihinde yapılan 12 sayılı toplantıda 9. karar olarak kabul edilmiştir. Ardından araştırmacılar tarafından ölçekler, Survey Monkey ve Google Forms uygulamalarına yüklenmiş ve online olarak otizmli çocuğu olan ebeveynlerden veriler toplanmıştır.

Verilerin analizinde SPPS 21 istatistik programı kullanılmıştır. Öncelikle verilerin normal dağılım gösterip göstermediği test edilmiştir. Elde verilerin çarpıklık ve basıklık indekslerinin istatistikleri incelendiğinde tüm değişkenlerin değerlerinin -3 ve +3 aralığında olduğu görülmüştür. Daha sonra yapılan analizlerde katılımcıların yaşam doyumu, algıladıkları sosyal destek ve umut düzeyleri arasındaki korelasyon incelenmiş, bu değişkenler arasında regresyon analizi yapılmıştır. Ayrıca yaşam doyumu, algılanan sosyal destek ve umut düzeyi ile yaş, 
ekonomik durum ve çalışma durumu gibi demografik değişkenler arasındaki ilişki t testi ve One Way ANOVA testi ile değerlendirilmiştir.

\section{BULGULAR}

Yaşam doyumu, algılanan sosyal destek ve umut değişkenlerinin birbirleri ile ve çeşitli demografik değişkenlerle ilişkilerini gösteren sonuçlar bölümde yer almaktadır.

Yaşam doyumu, algılanan çok boyutlu sosyal destek ve sürekli umut düzeylerine ilişkin ortalama ve standart sapmalar Tablo 2'de verilmişsir.

Tablo 2. Yaşam Doyumu, Algılanan Sosyal Destek ve Sürekli Umut Düzeyi Tanımlayıcı İstatistikleri

\begin{tabular}{lccc}
\hline & $\mathrm{n}$ & $\overline{\mathrm{X}}$ & $\mathrm{ss}$ \\
\hline Yaşam Doyumu & 151 & 12,80 & 4,46 \\
Algılanan Çok Boyutlu Sosyal Destek & 151 & 41,47 & 18,26 \\
Sürekli Umut & 151 & 40,07 & 10,87 \\
\hline
\end{tabular}

Tablo 2 incelendiğinde katılımcıların yaşam doyumu puan ortalamalarının 25 puan üzerinden 12,8; algılanan sosyal destek puan ortalamalarının 84 puan üzerinden 41,47; umut düzeyi puan ortalamalarının ise 96 puan üzerinden 40,07 olduğu görülmektedir. Puan ortalamalarına bakıldığında katılımcıların her bir ölçeklerden aldıkları puanların orta seviyede olduğu söylenebilir.

Yaşam doyumu, algılanan çok boyutlu sosyal destek ve sürekli umut puanlarına ilişkin Pearson Momentler Çarpımı korelasyon katsayıları Tablo 3'te sunulmuştur.

Tablo 3. Yaşam Doyumu, Algılanan Çok Boyutlu Sosyal Destek ve Umut Düzeyi Arasındaki İlişki

\begin{tabular}{lccc}
\hline & $\begin{array}{c}\text { Yaşam } \\
\text { Doyumu }\end{array}$ & $\begin{array}{c}\text { Algilanan Çok } \\
\text { Boyutlu Sosyal } \\
\text { Destek }\end{array}$ & $\begin{array}{c}\text { Umut } \\
\text { Düzeyi }\end{array}$ \\
\hline Yaşam Doyumu & 1,00 & 0,69 & 0,67 \\
Algılanan Çok Boyutlu Sosyal Destek & 0,69 & 1,00 & 0,66 \\
Umut Düzeyi & 0,67 & 0,66 & 1,00 \\
\hline
\end{tabular}

Korelasyon katsayıları yorumlanırken korelasyonun 0 ve 0.30 arasında olması ilişkinin bulunmadığı, 0.31 ve 0.49 arasında olması zayıf ilişki, 0.50 ve 0.69 arasında olması orta derecedeki bir ilişki, 0.70 ve 1.00 arasında olması ise yüksek bir ilişkinin olduğu şeklinde yorumlanmaktadır. Tablo 3 incelendiğinde katılımcıların yaşam doyumları ile algıladıkları sosyal destek arasında pozitif yönde ve umut düzeyleri ile negatif yönde orta derecede bir ilişki olduğu görülmektedir. Tabloda ayrıca algılanan sosyal destek ile umut düzeyi arasında da negatif yönde orta düzeyde bir iliş̧i olduğu görülmektedir.

Yaşam doyumunun yordayıcılarını belirlemek amacıyla çoklu regresyon analizi yapılmış ve analiz sonuçları Tablo 4'te gösterilmiştir.

Tablo 4. Yaşam Doyumunun Çoklu Regresyon Analizi

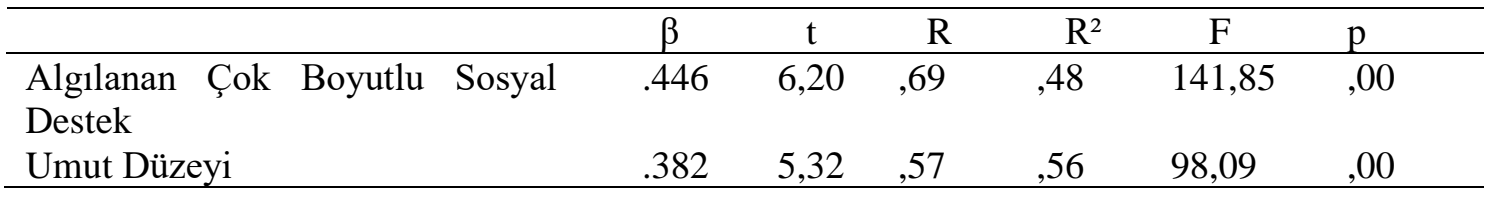


Tablo 4'te görüldüğü gibi algılanan çok boyutlu sosyal destek $(t=6,20, p<.05)$ ve umut düzeyi $(\mathrm{t}=5,32, \mathrm{p}<.05)$ otizmli çocuğu olan anne babaların yaşam doyumunu anlamlı düzeyde yordamaktadır. Yine tablo 4'e bakıldığında algılanan çok boyutlu sosyal desteğin yaşam doyumunun \%48,4'ünü açılamakta olduğu; sürekli umut ile birlikte algılanan sosyal desteğin toplam varsayın \%56,4'ünü yordadığı görülmektedir.

Katılımcıların çalışma durumlarına göre algılanan çok boyutlu sosyal destek, umut düzeyi ve yaşam doyumu düzeyleri arasında anlamlı bir ilişki olup olmadığına ilişkin $t$ testi yapılmıştır. Sonuçlar Tablo 5'te gösterilmektedir.

Tablo 5. Çalışma Durumu ile Algılanan Çok Boyutlu Sosyal Destek, Umut Düzeyi ve Yaşam Doyumu t Testi Tablosu

\begin{tabular}{|c|c|c|c|c|c|c|}
\hline & Çalışma Durumu & $\mathrm{n}$ & $\overline{\mathrm{X}}$ & ss & $\mathrm{t}$ & $\mathrm{p}$ \\
\hline \multirow{2}{*}{$\begin{array}{c}\text { Algilanan Çok Boyutlu Sosyal } \\
\text { Destek }\end{array}$} & Çalışmıyor & 99 & 36,33 & 15,66 & \multirow{2}{*}{$-4,86$} & \multirow{2}{*}{, 00} \\
\hline & Çalışıyor & 52 & 51,25 & 18,98 & & \\
\hline \multirow{2}{*}{ Umut Düzeyi } & Çalışmıyor & 99 & 37,13 & 10,50 & \multirow{2}{*}{$-4,91$} & \multirow{2}{*}{, 00} \\
\hline & Çalışıyor & 52 & 45,65 & 9,34 & & \\
\hline \multirow{2}{*}{ Yaşam Doyumu } & Çalışmıyor & 99 & 12,05 & 4,12 & \multirow{2}{*}{$-2,94$} & \multirow{2}{*}{,004 } \\
\hline & Çalışıyor & 52 & 14,25 & 4,77 & & \\
\hline
\end{tabular}

Tablo 5'e bakıldığında ebeveynlerin çalışma durumu ile algılanan çok boyutlu sosyal destek, sürekli umut ve yaşam doyumu düzeyleri arasında anlamlı bir ilişkinin olduğu görülmektedir $(\mathrm{p}<0.05)$. Herhangi bir işi olan katılımcıların algılanan çok boyutlu sosyal desteklerinin, umut düzeylerinin ve yaşam doyumlarının herhangi bir işte çalışmayan katılımcılara göre daha yüksek düzeyde olduğu saptanmıştır.

Katılımcıların yaşları ile algılanan çok boyutlu sosyal destek, sürekli umut ve yaşam doyumu düzeyleri arasında anlamlı bir ilişkinin olup olmadığına ilişkin tek yönlü varyans analizi yapılmıştır. Sonuçlar Tablo 6'da gösterilmiştir.

Tablo 6.Yaş ile Algılanan Çok Boyutlu Sosyal Destek, Umut Düzeyi ve Yaşam Doyumu Tek Yönlü Varyans Analizi

\begin{tabular}{lcccccc}
\hline & Yaş Grubu & $\mathrm{n}$ & $\overline{\mathrm{X}}$ & ss & $\mathrm{F}$ & $\mathrm{p}$ \\
\hline & $18-27$ & 6 & 34,83 & 10,99 & & \\
Algilanan Çok Boyutlu & $28-35$ & 45 & 43,64 & 18,39 & 1,61 &, 17 \\
Sosyal Destek & $36-42$ & 63 & 37,92 & 17,70 & & \\
& $43-50$ & 26 & 44,85 & 16,05 & & \\
& 51 ve üstü & 11 & 48,55 & 25,54 & & \\
& $18-27$ & 6 & 38,33 & 9,04 & & \\
Umut Düzeyi & $28-35$ & 45 & 40,98 & 12,18 & 0,93 &, 44 \\
& $36-42$ & 63 & 38,56 & 10,23 & & \\
& $43-50$ & 26 & 43,04 & 7,55 & & \\
& 51 ve üstü & 11 & 38,91 & 15,60 & & \\
Yaşam Doyumu & $18-27$ & 6 & 10,50 & 3,01 & & \\
& $28-35$ & 45 & 14,44 & 4,49 & & \\
& $36-42$ & 63 & 11,83 & 4,24 & 2,80 &, 02 \\
& $43-50$ & 26 & 12,81 & 4,32 & & \\
\hline
\end{tabular}

Tablo 6 incelendiğinde yaş değişkeni ile yaşam doyumu arasında anlamlı bir ilişkinin olduğu görülürken, algılanan çok boyutlu sosyal destek ve sürekli umut düzeyleri arasında anlamlı bir ilişki bulunmamıştır. 
Yaş ile yaşam doyumu arasındaki anlamlı ilişkinin hangi gruplardan kaynaklandığını anlamak için post hoc testlerinden Tukey testi yapılmıştır. Tukey testi sonuçlarına göre 28-35 yaş grubu katılımcıların yaşam doyumlarının 36-42 yaş grubu katılımcıların yaşam doyumlarından daha yüksek olduğu görülmüştür.

Katılımcıların ekonomik durumları ile algılanan çok boyutlu sosyal destek, sürekli umut ve yaşam doyumu düzeyleri arasında anlamlı bir ilişkinin olup olmadığına ilişkin tek yönlü varyans analizi yapılmıştır. Sonuçlar Tablo 7'de gösterilmiştir.

Tablo 7. Ekonomik Durum ile Algılanan Çok Boyutlu Sosyal Destek, Sürekli Umut ve Yaşam Doyumu Tek Yönlü Varyans Analizi

\begin{tabular}{lcccccc}
\hline & $\begin{array}{c}\text { Ekonomik } \\
\text { Durum }\end{array}$ & $\mathrm{n}$ & $\overline{\mathrm{X}}$ & ss & $\mathrm{F}$ & $\mathrm{p}$ \\
\hline \multirow{2}{*}{ Alg1lanan Çok Boyutlu } & Kötü & 62 & 32,89 & 13,84 & & \\
Sosyal Destek & Orta & 61 & 41,11 & 16,37 & 23,04 &, 000 \\
& İyi & 28 & 61,25 & 15,76 & & \\
\multirow{3}{*}{ Sürekli Umut } & Kötü & 62 & 34,06 & 9,60 & & \\
& Orta & 61 & 41,48 & 9,27 & 33,31 &, 000 \\
& İyi & 28 & 50,29 & 7,86 & & \\
Yaşam Doyumu & Kötü & 62 & 10,61 & 3,73 & & \\
& Orta & 61 & 13,31 & 3,98 & 31,34 &, 000 \\
\hline
\end{tabular}

Tablo 7 incelendiğinde ekonomik durum ile ebeveynlerin algılanan çok boyutlu sosyal destek, sürekli umut ve yaşam doyumu düzeyleri arasında anlamlı bir ilişki olduğu görülmektedir $(p<0.05)$. Değişkenler arasındaki anlamlı ilişkinin hangi gruplardan kaynaklandığını anlamak için post hoc testlerinden Tukey testi yapılmıştır. Algılanan sosyal destek ile ekonomik durum arasındaki ilişkiye ilişkin yapılan Tukey testine göre, ekonomik durumu düşük seviyede olan katılımcilar ile ekonomik durumu orta ve iyi seviyede olan katılımcilar arasında anlamlı bir fark olduğu görülmüştür. Aynı şekilde ekonomik durumu orta olan katılımcılar ile ekonomik durumu iyi olan katılımcılar arasında da fark olduğu bulunmuştur. Buna göre algılanan çok boyutlu sosyal destek düzeyinin ekonomik durum iyileştikçe arttığı söylenebilir.

Sürekli umut düzeyi ile ekonomik durum arasındaki ilişkiye ilişkin yapılan Tukey testine göre, ekonomik durumu düşük seviyede olan katılımcılar ile ekonomik durumu orta ve iyi seviyede olan katılımcılar arasında anlamlı bir fark olduğu görülmüştür. Aynı şekilde ekonomik durumu orta düzeyde olan katılımcılar ile ekonomik durumu iyi olan katılımcılar arasında da fark olduğu bulunmuştur. Buna göre sürekli umut düzeyinin ekonomik durum iyileştikçe arttığ söylenebilir.

Yaşam doyumu ile ekonomik durum arasındaki ilişkiye ilişkin yapılan Tukey testine göre, ekonomik durumu düşük düzeyde olan katılımcılar ile ekonomik durumu orta ve iyi düzeyde olan katılımcılar arasında anlamlı bir fark olduğu görülmüsstür. Aynı şekilde ekonomik durumu orta düzeyde olan katılımcilar ile ekonomik durumu iyi seviyede olan katılımc1lar arasında da fark olduğu bulunmuştur. Buna göre yaşam doyum düzeyinin ekonomik durum iyileştikçe arttığ1 söylenebilir.

\section{TARTIŞMA VE SONUÇ}

$\mathrm{Bu}$ araştırma, otizmli çocuğa sahip ebeveynlerin algılanan sosyal destek düzeyleri, umut düzeyleri ve yaşam doyumlarının birbirleri ile ve bazı demografik değişkenlerle ilişkilerinin incelenmesi amacıyla yürütülmüştür. 
Çalışmada algılanan sosyal destek düzeyleri, umut düzeyleri ve yaşam doyumları arasında orta düzeyde anlamlı olumlu bir ilişki bulunduğu ve umut düzeyi ile algılanan sosyal desteğin birlikte yaşam doyumunu önemli ölçüde yordadığı saptanmıştır. Umut düzeyi pozitif psikolojinin sağlıklı ruh halini yordayan ve depresyon ile büyük ölçüde ilişkili olan bir kavramdır (Faso, Neal-Beevers, ve Carlson, 2013). Alanyazında otizmli çocuğu olan ebeveynlerin umut düzeyleri ile depresyon düzeylerinin ilişkili olduğu, depresyon ve umutsuzluk azaldıkça yaşam doyumunun da arttığ bulunmuştur (Faso ve diğ., 2013; Ogston, Mackintosh ve Myers, 2011). Bu çalışmada katılımcıların yaşam doyumunu yordayan en önemli faktörün algılanan sosyal destek olduğu görülmüştür. Bu sonuç literatürde yer alan bazı çalışmaların sonuçları ile benzerlik göstermektedir. Araştırmalarda otizmli çocuğu olan anne babaların algıladıkları sosyal desteğin, depresyon ve umutsuzluk gibi psikolojik sıkıntılar ile yaşam doyumu ve kalitesinin de önemli bir belirleyicisi olduğu görülmektedir (Derguy ve diğ., 2016; Lu ve diğ., 2015; Marsack ve Samuel, 2017; Zablotsky ve diğ, 2013). Algılanan sosyal desteğin bu etkisinin, ebeveynlerin sorunlarını paylaşacak kişilere sahip olması ve bu sayede otizmli çocuğun sorumluğunun daha az yorucu ve daha kolay başa çıkılabilir olarak algılanmasından kaynaklandığı söylenebilir (Akkök, 2003).

$\mathrm{Bu}$ araştırmada otizmli çocuğu olan ebeveynlerin bir işe sahip olması, yaşı ve ekonomik durumu değişkenlerinin, algılanan sosyal destek, umut ve yaşam doyumları ile iliş̧kili oldukları bulunmuştur. Araştırmada ekonomik gelir getiren bir işte çalışma durumu ile yaşam doyumu, algılanan sosyal destek ve umut düzeyleri arasında anlamlı ilişki saptanmıştır. Bu sonuç da alanyazındaki bazı çalışmaların bulguları ile benzerlik göstermektedir. Kuru ve Piyal (2018) yaptıkları çalışmada otizmli çocuğu olan çalışan anne babaların algılanan sosyal destek ve yaşam kalitesi algılarının daha olumlu olduğunu saptamışlardır. Bunun yanında otizmli çocuğun ihtiyaçları ve bakımı ile aralıksız şekilde meşgul olmanın ebeveynlerin yaşam doyumu ve kalitesi algilarına olumsuz yansımaktadır (Lee, Harrington ve Louie, 2008; Meral, Cavkaytar, Turnbull ve Wang, 2013).

Araştırmada ailenin ekonomik durumunun algılanan sosyal destek, umut düzeyi ve yaşam doyumu ile ilişkili olduğu görülmüştür. Benzer şekilde, Meral ve diğ., (2013) yaptıkları çalışmada ailenin ekonomik düzeyi ile algıladıkları yaşam kalitesi arasında anlamlı bir ilişki olduğu belirtmiş̧lerdir. Ayrıca otizmli çocuğu olan anne babalarla yapılan farklı araştırmalarda ekonomik durumun depresyon ve umutsuzluk gibi psikolojik sıkıntılarla ilişkili olduğu saptanmıştır (Burrell, Ives, Unwin, 2017; Hock, Timm ve Ramish, 2012).

Çalışmanın bir diğer bulgusu da 28-35 yaş arasındaki katılımcıların yaşam doyumlarının 36-42 yaş arası katılımcılardan anlamlı düzeyde daha olumlu olmasıdır. Alanyazında bu bulgu ile benzer sonuçları olan çalışmalar yer almaktadır. Tehee, Honan ve Hevey (2009), yaptıkları çalışmada otizmli çocuğu olan anne babaların yaşları arttıkça yaşadıkları olumsuz psikolojik durumlarının da arttığını bildirilmiştir. Bu yaş grubundaki ebeveynlerin çocuklarının görece yaş olarak daha küçük olmasının ve ergenlik ve geçiş süreçlerini henüz yaşamamış olmalarının etkili olduğu düşünülmektedir.

\section{ÖNERILER}

$\mathrm{Bu}$ araştırmada algılanan sosyal desteğin otizmli çocuğu olan ebeveynlerin yaşam doyumlarını büyük ölçüde yordadığı saptanımıştır. Bu durum dikkate alındığında, ebeveynleri formal ve informal olarak destekleyen sistemlerin geliştirilmesin yararlı olacağı söylenebilir. Özellikle ebeveynler otizmin getirdiği mental ve duygusal zorluklara ilave olarak, finansal olarak ağır bir yük altına girmektedirler. Bu anlamda otizmli çocuğu olan ebeveynlere sosyal destek, eğitim ve finansal destek sağlayabilecek müdahaleler planlanmalı ve bu aileler aile eğitimleri ile desteklenmelidir. Araştırmada ayrıca otizmli çocuğu olan anne babaların algıladıkları sosyal destek, yaşam doyumu ve umut düzeylerinin birbirleri ile ilişkili olduğu görülmüsştür. Bu nedenle 
otizm bireyler ve aileleri ile çalışan alan uzmanlarının ebeveynlerin umut düzeylerini ve yaşam doyumlarını arttırmaya yönelik deneysel çalışmalar yapmaları önerilebilir.

Çalışmada ekonomik durum ve çalışma durumunun ebeveynlerin sosyal destek algısı, yaşam doyumu ve umut düzeyleri ile ilişkili olduğu görülmüş̧ür. Bu anlamda otizmli çocuğu olan ebeveynlerin istihdam yönünden desteklenmesinin yararlı olacağı söylenebilir. $\mathrm{Bu}$ nedenle istihdam programlarının hayata geçirilmesi önerilebilir.

Bu araştırma otizmli çocuğu olan ve çalışmaya gönüllü olarak katılan 151 anne baba ile sınırlıdır. Bunun yanında araştırma verileri online platformlar üzerinden elde edilmiştir ve bu açıdan sınırlıdır. Ayrıca araştırma algılanan çok boyutlu sosyal destek, yaşam doyumu ve umut düzeyi değişkenleri ile sınırlıdır. İleriki araştırmalara yönelik bu çalışmanın farklı özel gereksinim türünde çocuğu olan anne babalarla, farklı değişkenlerle, farklı veri toplama yöntemleri ve farklı araştırma desenleri ile gerçekleştirilmesi önerilebilir.

\section{KAYNAKÇA}

Akkök, F. (2003). Farklı özelliğe sahip olan çocuk aileleri ve ailelerle yapılan çalışmalar. (ed. A.Ataman) Özel Eğitime Giriş içinde Ankara: Gündüz Eğitim Yayıncılık.

American Psychiatric Association. (2013). Diagnostic and statistical manual of mental disorders (5th ed.). Washington, DC: American Psychiatric Association.

Barker, E. T., Hartley, S. L., Seltzer, M. M., Floyd, F. J., Greenberg, J. S. \& Orsmond, G. I. (2011). Trajectories of emotional well-being in mothers of adolescents and adults with autism. Developmental Psychology, 47(2), 551-561.

Bearss, K., Burrell, T. L., Stewart, L. M. \& Scahill, L. (2015). Parent training in autism spectrum disorder: what's in a name? Clinical Child and Family Psychology Review, $18(2), 170-182$.

Burrell, A., Ives, J. \& Unwin, G. (2017). The experiences of fathers who have offspring with autism spectrum disorder. Journal of Autism and Developmental Disorders, 47(4), $1135-1147$.

Cho, S. \& Kahng, S. K. (2015). Predictors of life satisfaction among caregivers of children with developmental disabilities in South Korea. Asian Social Science, 11(2), 154-166

Cidav, Z., Marcus, S. C. \& Mandell, D. S. (2012). Implications of childhood autism for parental employment and earnings. Pediatrics, 129(4), 617-623.

Cunningham, S., Gunn, T., Alladin, A. \& Cawthorpe, D. (2008). Anxiety, depression and hopelessness in adolescents: A structural equation model. Journal of the Canadian Academy of Child and Adolescent Psychiatry, 17(3), 137-144.

Çengelci, B. (2009). Otizm ve down sendromlu çocuğa sahip annelerin kaygı, umutsuzluk ve tükenmişlik duygularının karşılaştırılması. Ege Eğitim Dergisi, 10(2), 1-22.

Dağl1, A. ve Baysal, N. (2016). Yaşam doyumu ölçeğinin Türkçeye uyarlanması: Geçerlik ve güvenirlik çalışması. Elektronik Sosyal Bilimler Dergisi, 15(59), 1250-1262.

Derguy, C., Bailara, K., Michel, G., Roux, S. \& Bouvard, M. (2016). The need for an ecological approach to parental stres in autism spectrum disorders: The combined role of individual and environmental factors. Journal of Autism and Developmental Disorders, 46(6), 1895-1905.

Diener, E. (1984). Subjective well-being. Psychological Bulletin, 95, 542-575. 
Diener, E., Emmons, R. A., Larsen, R. J. \& Griffin, S. (1985). The satisfaction with life scale. Journal of Personality Assessment, 49(1), 71-75.

Ekas, N.V., Lickenbrock, D. M. \& Whitman, T. L. (2010). Optimism, social support, and wellbeing in mothers of children with autism spectrum disorder. Journal of Autism and Developmental Disorder, 40(10), 1274-1284.

Estes, A., Munson, J., Dawson, G., Koehler, E., Zhou, X., \& Abbott, R. (2009). Parenting stress and psychological functioning among mothers of preschool children with autism and developmental delay. Autism, 13(4), 375-387.

Farrugia, D. (2009). Exploring stigma: Medical knowledge and the stigmatisation of parents of children diagnosed with autism spectrum disorder. Sociology of Health \& Ilness, 31(7), 1011-1027.

Faso, D. J., Neal-Beevers, A. R. \& Carlson, C. L. (2013). Vicarious futurity, hope, and wellbeing in parents of children with autism spectrum disorder. Research in Autism Spectrum Disorders, 7(2), 288-297.

Hayes, S. A. \& Watson, S. L. (2013). The impact of parenting stress: a meta-analysis of studies comparing the experience of parenting stress in parents of children with and without autism spectrum disorder. Journal of Autism and Developmental Disorders, 43(3), $629-642$.

Hines, M., Balandin, S. \& Togher, L. (2014). The stories of older parents of adult sons and daughters with autism: Abalancing act. Journal of Applied Research in Intellectual Disabilities, 27(2), 163-173.

Hock, R. M., Timm, T. M., \& Ramisch, J. L. (2012). Parenting children with autism spectrum disorders: A crucible for couple relationships. Child and Family Social Work, 17(4), 406-415.

Hoefman, R., Payakachat, N., van Exel, J., Kuhlthau, K., Kovacs, E., Pyne, J. \& Tilford, J. M. (2014). Caring for a child with autism spectrum disorder and parents' quality of life: Application of the CarerQol. Journal of Autism and Developmental Disorders, 44(8), 1933-1945.

Karadağ, G. (2009). Engelli çocuğa sahip annelerin yaşadıkları güçlükler ile aileden algıladıkları sosyal destek ve umutsuzluk düzeyleri. TAF Preventive Medicine Bulletin, 8(4), 315-322.

Karasar, N. (2016). Bilimsel Araştırma Yöntemi. Ankara: Nobel.

Karpat, D. ve Girli, A. (2012). Yaygın gelişimsel bozukluk tanılı çocukların anne babalarının yas tepkilerinin, evlilik uyumlarının ve sosyal sestek algılarının incelenmesi. Ankara Üniversitesi Eğitim Bilimleri Fakültesi Özel Ĕ̈itim Dergisi, 13(2), 69-85.

Khanna, R., Madhavan, S. S., Smith, M. J., Patrick, J. H., Tworek, C., \& Becker Cottrill, B. (2011). Assessment of health-related quality of life among primary caregivers of children with autism spectrum disorders. Journal of autism and developmental disorders, 41(9), 1214- 1227.

Khun, J., Ford, K. \& Dawalt, L. S. (2017). Brief report: Mapping systems of support and psychological well-being of mothers of adolescents with autism spectrum disorders. Journal of Autism and Developmental Disorders, 48(3), 1-7.

Kuru, N. \& Piyal, B. (2018). Perceived social support quality of life of parents of children with autism. Nigerian Journal of Clinical Practice, 21(9), 1182-1189. 
Landis, D., Gaylord-Harden, N.K., Malinowski, S.L., Grant, K.E., Carleton, R.A. \& Ford, R.E. (2007). Urban adolescent stress and hopelessness. Journal of Adolescence 30(6), 10511070 .

Lee, L., Harrington, R. \& Louie, B. (2008). Children with autism: Quality of life and parental concerns. Journal of Autism and Developmental Disorders, 38(6), 1147-1160.

Lu, M., Yang, G., Skora, E., Wang, G., Cai, Y., Sun, Q. \& Li, W. (2015). Self-esteem, social support, and life satisfaction in Chinese parents of children with autism spectrum disorder. Research in Autism Spectrum Disorders, 17, 70-77.

Marsack, C. N. \& Perry, T. E. (2018). Aging in place in every community: Social exclusion experiences of parents of adult children with autism spectrum disorder. Research on Aging, 40(60), 535-557.

Marsack, C. N. \& Samuel, P. S. (2017). Mediating effects of social support on quality of life for parents of adults with autism. Journal of Autism and Developmental Disorders, 47(8), 2378-2389.

Mazurek, M. O. (2014). Loneliness, friendship, and well-being in adults with autism spectrum disorders. Autism, 18(3), 223-232.

McStay, L.R., Dissanayake, C., Scheeren, A., Koot, M.H. \& Begeer, S. (2014). Parenting stress and autism: The role of age, autism severity, quality of life and problem behaviour of children and adolescents with autism. Autism, 18(5) 502-510.

Meral. B.F. ve Cavkaytar, A. (2012). Çok boyutlu algılanan sosyal destek ölçeğinin psikometrik özelliklerinin otizmli çocuk aileleri üzerinden incelenmesi. $E$ International Journal of Educational Research, 3(4), 20-32.

Meral, B.F., Cavkaytar, A., Turnbull, A.P. \& Wang, M. (2013). Family quality of life of Turkish families who have children with intellectual disabilities and autism. Research \& Practice for Persons with Severe Disabilities, 38(4), 233-246.

Naci, E. \& Koletsi, M. (2021). The relationship between cognitive distortions, hopelessness, and depression in parents of children diagnosed with autism spectrum disorder in Albania. Dialogues in Clinical Neuroscience \& Mental Health, 4(2) 81-90.

Nicholas, D. B., MacCulloch, R., Roberts, W., Zwaigenbaum, L. \& McKeever, P. (2020). Tensions in maternal care for children, youth, and adults with autism spectrum disorder. Global Qualitative Nursing Research, 7, 1-10.

Ogston, P. L., Mackintosh, V. H. \& Myers, B. J. (2011). Hope and worry in mothers of children with an autism spectrum disorder or down syndrome. Research in Autism Spectrum Disorders, 5(4), 1378-1384.

Özkubat, U., Özdemir, S., Selimoğlu, G.Ö. \& Töret, G. (2014). Otizme yolculuk: Otizmli çocuğa sahip ebeveynlerin sosyal destek algılarına ilişkin görüşleri. Ondokuz Mayıs Üniversitesi Ĕgitim Fakültesi Dergisi, 33(1) 323-348.

Oti-Boadi, M., Asante, K. O. \& Malm, E. K. (2020). The experiences of ageing parents of young adults with autism spectrum disorders (ASD). Journal of Adult Development, 27(1), 58-69.

Patterson, J. (2002). Integrating family resilience and family stress theory. Journal Of Marriage and Family, 64(2), 349-360.

Pozo, P., Sarria, E., \& Brioso, A. (2014). Family quality of life and psychological well-being in parents of children with autism spectrum disorders: A double ABCX model. Journal of Intellectual Disability Research, 58(5), 442-458. 
Rivard, M., Terroux, A., Parent-Boursier, C. \& Mercier, C. (2014). Determinants of stress in parents of children with autism spectrum disorders. Journal of autism and developmental disorders, 44(7), 1609-1620.

Robertson, S. M. (2010). Neurodiversity, quality of life, and autistic adults: shifting research and professional focuses onto real-life challenges. Disability Studies Quarterly, 30(1), 1-21.

Sabih, F. \& Sajid, W.B. (2008) There is significant stress among parents having children with autism. The Journal of the Pakistan Medical Association, 33(2), 214-216.

Sencar, B. (2007) Otistik çocuğa sahip ailelerin alglladıklart sosyal destek ve stres düzeyleri arasındaki ilişkinin incelenmesi. Yayımlanmamış Yüksek Lisans Tezi. Dokuz Eylül Üniversitesi, Eğitim Bilimleri Enstitüsü, İzmir.

Snyder, C. R., LaPointe, A. B., Crowson, J. J. \& Early, S. (1998). Preferences of high and lowhope people for self-referential input. Cognition \& Emotion, 12(6), 807-823.

Swaab, L., McCormack, L. \& Campbell, L. E. (2017). Distress and psychological growth in parenting an adult child with autism spectrum disorder and aggression. Advances in Neurodevelopmental Disorders, 1(4), 260-270.

Tanaka, E., Sakamoto, S., Ono, Y., Fujihara, S. \& Kitamura, T. (1996). Hopelessness in a community population in Japan. Journal of Clinical Psychology, 52(6), 609-615.

Tarhan, S.ve Bacanl1, H. (2015). Sürekli umut ölçeğinin Türkçeye uyarlanması: Geçerlik ve güvenirlik çalışması. The Journal of Happiness \& Well-Being, 3(1), 1-14.

Tehee E, Honan, R. \& Hevey, D. (2009). Factors contributing to stress in parents of individuals with autistic spectrum disorders. Journal of Applied Research in Intellectual Disabilities, 22(1), 34-42.

Tunç, S. ve Özkardaş, O. (2020). Otizmli çocuğu olan annelerde algılanan sosyal desteğin anksiyete ve ebeveyn tükenmişliği üzerindeki etkisi. Social Sciences Research Journal, 9(4), 247-253.

Vasilopoulou, E., \& Nisbet, J. (2016). The quality of life of parents of children with autism spectrum disorder: A systematic review. Research in Autism Spectrum Disorders, 23, $36-49$.

Vetrayan, J., Daud, A. \& Paulraj, S.J. (2013). Level of hopelessness among parents with autistic children. Indian Journal Of Health and Wellbeing, 4(4), 875-878.

Yorke, I., White, P., Wetson, A., Rafla, M., Charman, T. \& Simonoff, E. (2018). The association between emotional and behavioral problems in children with autism spectrum disorder and psychological distress in their parents: A systematic review and meta-analysis. Journal of Autism and Developmental Disorders, 48(10), 3393-3415.

Zablotsky, B., Bradshaw, C. P. \& Stuart, E. A. (2013). The association between mental health, stress, and coping supports in mothers of children with autism spectrum disorders. Journal of Autism Developmental Disorders, 43(6), 1380-1393.

Zimet, G. D., Dahlem, N. W., Zimet, S. G. \& Farley, G. K. (1988). The Multidimensional Scale of Perceived Social Support. Journal of Personality Assessment, 52(1), 30-41.

\section{EXTENDED ABSTRACT}

\section{Introduction}

Autism is a developmental disorder characterized by social skills, communication disorders, and repetitive behaviors. Autism brings with it a number of problems in issues such as 
self-care, socialization, communication, daily life skills and independent living for both individuals with the disorder and their families. According to the studies conducted, it has been reported that parents of children with autism experience more psychological difficulties and their life satisfaction is more negative than parents of children with normal development.

The factor that has the most negative impact on the problems experienced by parents is the intensity and severity of the problem behaviors of the child with autism. It is stated that the parents of children with autism who have high level of problem behaviors experience emotional states such as depression and hopelessness more intensely, and their perceived life satisfaction and quality are more negative.

However, despite all these, it is observed that parents of children with autism can cope with these problems and adapt to living with a child with autism. It is stated that one of the most important factors that facilitates the adaptation to a child with autism is perceived social support. Studies have found that parents with more positive perceived social support have less psychological distress and their perceptions of life satisfaction and quality of life are more positive.

In this study, it is aimed to investigate the relationship between life satisfaction, perceived social support and hope levels of parents with children with autism and with each other and with some variables.

\section{Method}

In this study, scanning method, one of the descriptive research models, was used. The study group of the study consisted of 151 volunteer parents who have a child with autism. Data collection tools used in the study are Dispositional Hope Scale, Perceived Multidimensional Social Support Scale, Life Satisfaction Scale and Personal Information Form created by the researchers.

The research was conducted in the fall semester of the 2018-2019 academic year. In order to apply the scales, permissions were obtained from the researchers who conducted the adaptation, validity and reliability studies of the scales. Later, an ethics committee application was made to Dokuz Eylül University Institute of Educational Sciences. The application for the ethics committee was accepted as the 9th decision at the meeting number 12 held on 20/12/2018. Then, the scales were uploaded to Survey Monkey and Google Forms applications by the researchers, and data were collected online from parents of children with autism.

\section{Results}

The data obtained from the research were analyzed for the purposes of the research. According to statistical analysis, life satisfaction, perceived social support and hope levels of parents with children with autism are moderate.

According to the correlational analysis, there is a moderate correlation between life satisfaction, social support and hope levels of parents with children with autism.

The multidimensional social support perceived as a result of the regression analysis explains $48.4 \%$ of life satisfaction; It is seen that perceived social support together with permanent hope predicts $56.4 \%$ of the total assumption.

The t-test and one-way ANOVA test regarding the relationship between the demographic information of the parents with children with autism and the dependent variables were performed. As a result of the analysis made;

It was determined that working parents' life satisfaction, perceived social support and hope levels were more positive than non-working parents. 
It was found that as the economic situation improved, the life satisfaction, perceived social support and hope levels of the parents also increased.

As a result of the research, it was seen that $48 \%$ of parents' life satisfaction can be explained by perceived social support perception. This result is similar to the results of some studies in the literature. Studies show that the social support perceived by parents of children with autism is an important determinant of psychological distress such as depression and hopelessness, and life satisfaction and quality.

\section{Discussion and Conclusion}

At the end of the study, it was determined that there is a significant relationship between economic status and employment status and life satisfaction, perceived social support and hope level. Similar results were found in different studies in the literature. It is thought that working in a job has a social support effect on its own as a reason for this situation.

In conclusion, considering that the perceived social support in this study predicts the life satisfaction of parents with children with autism to a great extent, it can be said that developing systems that support parents formally and informally would be beneficial. In addition to the mental and emotional burdens of autism, parents in particular face a heavy financial burden. In this sense, interventions that can provide social support, education and financial support to parents with children with autism should be planned and the families of these families should be supported. 